\title{
Effect of the COVID-19 pandemic on anxiety, depression, hopelessness, and sleepiness levels of obstetricians and gynecologists in Turkey
}

\author{
Seda Keskin ${ }^{1}$, Deha Denizhan Keskin ${ }^{1}$, Sedat Bostan ${ }^{2}$ \\ ${ }^{I}$ Obstetrics and Gynecology Department, Medical Faculty, Ordu University Altınordu, Ordu, Turkey \\ ${ }^{2}$ Health Management Department, Faculty of Health Sciences, Ordu University Altınordu, Ordu, Turkey
}

Received: 2020-11-07.

Accepted: 2021-02-10

This work is licensed under a Creative Commons Attribution 4.0 International License

J Clin Med Kaz 2021; 18(2):14-19

Corresponding author:

Seda Keskin.

E-mail: adesniksek@gmail.com; ORCID: 0000-0002-5640-4552

\begin{abstract}
Introduction: The coronavirus disease 2019 (Covid-19), emerged as a severe respiratory system disease in Wuhan city of China in December 2019 and suddenly spread through the world, so called a pandemic by World Health Organisation. The rapid transmission of Covid-19 pandemic increased the workload of healthcare staff. Additionally to workload, unknowns of the disease like treatment strategies, tips of protection methods have increased the distress of healthcare workers and have the risk to detoriate the mental status. All that psychological and physical stress factors alter the anxiety level, sleep quality and mood of the healthcare workers.
\end{abstract}

Material and methods: In the study, a survey composed of sociodemographic features, Beck Anxiety Scale, Beck Depression Scale, Beck Hopelessness Scale and Epworth Sleepiness Scale of participants were used as data collection tool. The internet survey is hold on from 18th April to 2nd May 2020 and completed survey count arrived to number 122.

Results: According to results, $20.5 \%$ moderate and $8.2 \%$ of the physicians have shown severe depression signs. When anxiety levels were examined $83.7 \%$ of the physicians have displayed mild signs, 9.8\% moderate and $6.5 \%$ have displayed severe anxiety signs. When hopelessness of the physicians were investigated, $29.5 \%$ of them have moderate and $8.2 \%$ have severe hopelessness signs. According to sleepiness situations, $20.5 \%$ of them have shown severe sleepiness signs.

Conclusion: As anxiety levels of obstetricians and gynecologists have increased at pandemic period, depression levels have increased strongly; hopes of physicians have decreased and slept off.

Key words: Covid-19, obstetricians, gynecologists, anxiety, depression

\section{Introduction}

The coronavirus disease 2019 (Covid-19), emerged as a severe respiratory system disease in Wuhan city of China in December 2019 [1] and suddenly spread through the world, so called pandemic by World Health Organisation [2]. Pandemic is very contagious infectious disease with increased morbidity and mortality over large geographic locations, resulting impairment in economics, society and politics. In 1918 Spanish flu, in 1957 Asian flu, in 1968 Hong Kong flu and in 2009 swine flu were pandemics variating in morbidity and mortality in the last century [3]. The spread of Covid-19 pandemic was faster than all known epidemic or pandemic all over the world containig SARS and MERS in the last two decades [4]. Pandemic risk is inreasing in the last century as a result of global travelling, urbanization, alteration of agricultural fields and overuse of natural environment [5]. Pandemics give rise to diffuculties in healthcare sector and also other fields like diagnosis and treatment of disease in time, basic maintenance needs, contact tracking of suspicious cases, quarantine and isolation procedures despite of arrangements and development of health systems [6,7]. 
The rapid transmission of Covid-19 pandemic, transmission to lots of people over the world in a very short time and high mortality rate of disease increased the workload of healthcare staff proportionally. Additioanlly to workload, unknowns of the disease like treatment strategies, tips of protection methods have increased the distress of healthcare workers, and have the risk to detoriate the mental status [8]. It is known that during SARS-Cov-2 epidemic, hospital staff especially doctors and nurses were under more risk of psychological disorders following participitating in the follow-up periods of SARS patients [9]. Complexity of the situation for staff is not only having accelerating workload but also anxiety of contagion for their families, diffuculty of adapting new illness and changing protocols over a few days or a week and also concern about quantity and quality of personal protective equipments, worry about patients becoming quickly sick and also anxiety for colleagues. All that psychological and physical stress factors alter the anxiety level, sleep quality and mood of the healthcare workers.

Acute stress reactions which include emotional, cognitive, physical and social reactions may be prominent when they present but generally recovery happens within a couple of week. These reactions are normal and awareness of staff about these feelings decrease distress [10]. A new research related to post traumatic stress disorder (PTSD) suggesting the PTSD ratio among resuscitation providers at baseline as 9.6\% [11]. In parallel to that information, expected PTSD may be bigger than $10 \%$ in frontline healthcare givers.

While the Covid-19 pandemic gradually spreads all over the world with its knowns and unknowns, diagnosis and treatment strategies changes periodically, immunisation studies are continuing all over the world with a great speed, governments taking rigid precautions sometimes and than unloose these limitations with economic concerns or demand of public; health care workers - brave battles- getting more tired, more anxious and more hopeless with the following duration.

There is an obscurity about difference in daily clinical and surgical applications how affected their anxiety, sleep, depression and hopelessness situations. The present study is designated to understand how changes in the working practice and healthcare concern during Covid-19 pandemic affected the anxiety, sleep, depression and hopelessness situations of obstetricians and gynecologists.

\section{Material and methods \\ Population and sampling:}

The population of study is composed of obstetricians and gynecologists working at different health institutions in Turkey. Exclusion criteria was depression or other mood disorders which was diagnosed earlier. Inclusion criteria was being obstetrician and gynecologist actively working in Turkey whether studying in pandemic hospital or not. The internet survey method is used in the study to provide partcipation of obstetricians and gynecologists. One hundred-twenty two obstetricians and gynecologists have participated in the study. Fifty-four percent of participitating doctors was female and $45.1 \%$ male; $45.9 \%$ of doctors was $<39$ years old, $33.6 \%$ of them was $40-49$ years old and $20.5 \%$ of doctors was 50 years old and over age group; $23.8 \%$ of obstetricians and gynecologists was assistant doctor, according to professional task years $10.7 \%<5$ years, $21.3 \%$ 6-10 years, $20.5 \% 11-15$ years, $10.7 \% 16-20$ years and $13.1 \%$ $>21$ years.

\section{Data collection tools, process and analysis of scales}

In the study, a survey composed of socio-demographic features, Beck Anxiety Scale, Beck Depression Scale, Beck Hopelessness Scale and Epworth Sleepiness Scale of participants were used as data collection tool. These tools were validated in Turkish. The Ethical Committee decision of the study for applying survey was taken at 16th April. The survey which was formed on internet media was shared with vocational sharing and support groups composed within the obstetricians and the gynecolgists in Turkey and practitioners were asked to complete the survey. The internet survey is hold on from 18th April to 2nd May 2020, and completed survey count arrived to number 122. That extraordinary process, having stress and busyness of the physicians were the limitation of data collection.

Beck Depression Inventory-II is a self-scored questionnaire for measuring depression severity in psychiatric patients and also the normal population. It has 21 , four-option multiple-choice questions based on a score of zero to three. This questionnaire identifies different degrees of depression from mild to severe and measures the physical, behavioral, and cognitive symptoms of depression. Beck depression score 0-9 is showing minimal depression; 10-16 mild depression; 17-29 moderate depression; 30-63 severe depression. Beck anxiety score lesser than 21 showing mild anxiety; score of 22-35 is showing moderate anxiety; 36-63 score is showing severe anxiety. Beck hopelessness scores ranging from: 0 to 6 as are considered as mild hopelessness, 7 to 13 scores as moderate hopelessness, and scores greater than 14 identify severe hopelessness. According to Epworth sleppiness scale, 0-9 mild sleepiness daytime symptoms; 10-24 severe sleepines daytime symptoms.

Because Beck Anxiety, Beck Depression and Epworth Scales are quadruple degreed scales, validity of the scales were verificated via factor analysis. Validity is defined as the extent to which a concept is accurately measured in a quantitative study. [12]. Passer et al. evaluated Beck's Depression Inventory and reported that its internal consistency (Cronbach's alpha) was 0.92 , its validity is 0.75 with one-week interval and its correlation coefficients vary from 0.30 to 0.76 . Because Beck Hopelessness scale is a scale composed of yes and no replies, analysis of reliability and validity were not done.

KMO (Kaiser-Meyer-Olkin) sampling coefficient is seen as above 0.80 for each three scale. When KMO is approaching to 1 , sampling size used in the study is arriving perfect and the value being 0.80 is accepted as very good and 0.90 is accepted as perfect. A Kaiser-Meyer-Olkin (KMO) test is used in research to determine the sampling adequacy of data that are to be used for Factor Analysis [13]. Bartlett's Test of Sphericity result which is used to evaluate the adequacy of survey to factor analysis is also found as significant $(\mathrm{p}=0.000)$. According to these evaluations, scales were found to be suitable for factor analysis. Factor loads of three scales were found quitely high and power of total variance explaination was found enough as being 58.989, 48.36 and 47.672. Because of Cronbach's alpha reliability coefficients of scales being above 0.80 , it was determined that scales were high grade reliable.

For analysing the results of the study, SPSS 22 statistical software package was used. Analyzes were carried out in a $95 \%$ $(p=0.05)$ confidence interval. Descriptive statistical methods and correlation analyzes had been used in the study. 


\section{Results}

Socio-demographic charecteristics of the population is presented in Table 1. According to the findings of the study, $36.9 \%$ of obstetricians and gynecoogists are occupying at health ministry hospitals, $32.8 \%$ at faculty hospitals, $18.8 \%$ at private hospitals and $11.5 \%$ at private clinics. Sixty two point three percent of the physicians are working at pandemic hospital, $31.1 \%$ at hospitals having no Covid-19 patients and $6.6 \%$ of physicians are working at hospitals not pandemic but having some Covid-19 cases. Seventy two point one percent of physicians have met Covid-19 suspicious patient, $37.7 \%$ of physicians have met patient with Covid-19 diagnosis; 42 of physicians have been made Covid-19 test, and 5 of them had positive test results.

\begin{tabular}{|c|c|c|}
\hline $\begin{array}{l}\text { Socio-demographic charecte } \\
\text { population }\end{array}$ & istic & \\
\hline Variables & $\mathrm{N}$ & $\%$ \\
\hline \multicolumn{3}{|l|}{ 1. Gender } \\
\hline Female & 67 & 54,9 \\
\hline male & 55 & 45,1 \\
\hline \multicolumn{3}{|l|}{ 2. Age } \\
\hline Under 39 & 56 & 45,9 \\
\hline $40-49$ & 41 & 33,6 \\
\hline Over 50 & 25 & 20,5 \\
\hline \multicolumn{3}{|l|}{ 3. Occupational years } \\
\hline Asistant doctor & 29 & 23,8 \\
\hline Under 5 years & 13 & 10,7 \\
\hline $6-10$ years & 26 & 21,3 \\
\hline $11-15$ years & 25 & 20,5 \\
\hline $16-20$ years & 13 & 10,7 \\
\hline Over 21 years & 16 & 13,1 \\
\hline \multicolumn{3}{|l|}{ 4. Hospital Type } \\
\hline Health Ministry Hospitals & 45 & 36,9 \\
\hline University Hospitals & 40 & 32,8 \\
\hline Private Hospitals & 23 & 18,8 \\
\hline Private Clinics & 14 & 11,5 \\
\hline \multicolumn{3}{|l|}{ 5. Degree or title } \\
\hline Asistant doctor & 31 & 25,4 \\
\hline Specialist & 67 & 54,9 \\
\hline Assistant Professor & 11 & 9,0 \\
\hline Associated Professor or Proffesor & 13 & 10,7 \\
\hline \multicolumn{3}{|l|}{ 6. Are you working in pandemic hospital? } \\
\hline Yes & 76 & 62,3 \\
\hline No & 38 & 31,1 \\
\hline No, but Covid-19 suspicious patients are accepted & 8 & 6,6 \\
\hline \multicolumn{3}{|c|}{ 7. Have you ever came across Covid-19 suspicious patient? } \\
\hline Yes & 88 & 72,1 \\
\hline No & 34 & 27,9 \\
\hline \multicolumn{3}{|c|}{ 8. Have you ever came across Covid-19 diagnosed patient? } \\
\hline Yes & 46 & 37,7 \\
\hline No & 76 & 62,3 \\
\hline \multicolumn{3}{|l|}{ 9. Have you ever been tested for Covid-19? } \\
\hline Yes, result was negative & 37 & 30,3 \\
\hline Yes, result was positive & 5 & 4,1 \\
\hline No & 50 & 65,6 \\
\hline
\end{tabular}

Results of Beck Anxiety, Beck Depression, Beck Hopelessness and Epworth Sleepiness Scales which have been applied to determine how the obstetricians and gynecologists are affected from stress that have been brought out by the Covid-19 pandemic and pandemic conditions and also factors like changing working conditions, are given below.

\begin{tabular}{|l|l|l|}
\hline & Number & Percent (\%) \\
\hline Beck Anxiety Scales & & \\
\hline Mild Anxiety (0-21) & 102 & 83.7 \\
\hline Moderate Anxiety (22-35) & 12 & 9.8 \\
\hline Severe Anxiety (36-63) & 8 & 6.5 \\
\hline Beck Depression Scales & & \\
\hline Minimal depression (0-9) & 50 & 41 \\
\hline Mild depression (10-16) & 37 & 30.3 \\
\hline Moderate depression (17-29) & 25 & 20.5 \\
\hline Severe depression (30-63) & 10 & 8.2 \\
\hline Beck Hopelessness Scales & & \\
\hline Mild hopelessness (0-6) & 76 & 62.3 \\
\hline Moderate hopelessness (7-13) & 36 & 29.5 \\
\hline Severe hopelessness (14-20) & 10 & 8.2 \\
\hline Epworth Sleepiness Scales & & \\
\hline Mild Sleepiness (0-9) & 97 & 79.5 \\
\hline Severe Sleepiness (10-24) & 25 & 20.5 \\
\hline & &
\end{tabular}

Beck Anxiety scores have been demonstrated in Table 2. According to the Table $2 ; 83.7 \%$ of the physicians have displayed mild signs, $9.8 \%$ moderate and $6.5 \%$ have displayed severe anxiety signs.

The results of Beck Depression scale have given in Table 2. According to Table $2 ; 41 \%$ of the pyhsicians have shown minimal depression signs, $30.3 \%$ mild, $20.5 \%$ moderate and $8.2 \%$ of the physicians have shown severe depression signs.

The results of Beck hopelessness scale have given in Table 2. According to results, $62.3 \%$ of physicians have mild, $29.5 \%$ of them have moderate and $8.2 \%$ have severe hopelessness signs.

The results of Epworth Sleepiness scale have given in Table 2. According to results, $79.5 \%$ of physicians have shown mild and $20.5 \%$ of them have shown severe sleepiness signs.

The relationship between anxiety, depression, hopelessness and sleepiness levels of physicians was examined by Pearson correlation analysis. The result of analysis is given in Table 3.

According to the correlation analysis result; As the anxiety level of physicians increases, their depression levels increase at a high (0.829) level; hopefulness levels decrease at a low level (-0.202); sleepiness levels were increasing at a low level (0.242). As the depression level of physicians increases, the level of hope decreases at a low level (-0.197); insomnia level increases at a low level (0.293). As the hope level of physicians increases, the level of insomnia decreases at a low level $(-0.157)$. As a result; it was found that there is a high linear relationship between the anxiety and depression levels of physicians; but there is a low correlation between other factors.

Socio-demographic characteristics of the obstetricians (age, gender, year of employment, title, hospital type and the hospital being studied is a pandemic hospital) was not effective on anxiety, depression, hopelessness and insomnia. It is noteworthy as it shows that their clinical approach is the main determinant on their practice.

Consequently, as anxiety levels of obstetricians and gynecologists have increased at pandemic period, depression levels have increased strongly; hopes of physicians have decreased and slept off. As depression levels of obstetricians and gynecologists have increased, hopes of physicians have decreased and sleep problems have increased.

\section{Discussion}

Each healthcare worker, every class of society and all grades of physicians in clinics are at risk, in the pandemic Journal of Clinical Medicine of Kazakhstan: 2021 Volume 18, Issue 2 


\begin{tabular}{|l|l|l|l|l|l|}
\hline & & Beck Anxiety & Beck Depression & Beck Hopelessness & Epworth Sleep \\
\hline Beck Anxiety & Pearson Correlation & 1 & & & \\
\hline & Sig. (2-tailed) & & & & \\
\hline & $\mathrm{N}$ & 122 & & & \\
\hline Beck Depresion & Pearson Correlation &, $829\left(^{* *}\right.$ & 1 & & \\
\hline & Sig. (2-tailed) &, 000 & & & \\
\hline & N & 122 & 122 & & \\
\hline Beck Hope & Pearson Correlation &,$- 202\left(^{*}\right)$ &,$- 197\left(^{*}\right)$ & & \\
\hline & Sig. $(2$-tailed) &, 026 &, 031 & & \\
\hline & N & 122 & 122 & 122 & \\
\hline Epworth Sleep & Pearson Correlation &, $242\left(^{* *}\right.$ &, $293\left(^{* *}\right)$ &,- 157 & \\
\hline & Sig. (2-tailed) &, 008 &, 001 &, 083 & 1 \\
\hline & N & 122 & 122 & 122 & 122 \\
\hline
\end{tabular}

* Correlation is significant at the 0.05 level (2-tailed).

** Correlation is significant at the 0.01 level (2-tailed).

process which have grown up globally and rapidly. Beyond the infection risk, economical and social diffuculties and psyhcologic disturbances come up with these problems are of top priority. If in that investigation, pshycologic reactions and mental status of a condansated group of physicians, obstericians and gynecologists, have been examined.

Even though gynecologists and obstetricians are not in the forefront like emergency, infectious diseases and intensive care physicians in this process; while the workload of each branch and the number of applications to the hospital are decreasing, obstetricians' and gynecologists' close contact with the patient and the hospital environment do not decrease. The non-deferral conditions such as pregnancy and follow-up processes of important cancers of women continue. Also, especially in the 2nd stage during labor, intensive aerosol exposure continues and also in an event that is very spesific and important in women's life such as birth, close contact with the pregnant is inevitable and social distance concept may lose its validity in the delivery room. All these heavy working conditions may deteroiate the psychology of the obstetricians and gynecologists. That was the reason for proceeding this survey investigation.

In addition, there are frightening data in the literature regarding the potential for transmission and contamination of healthcare professionals in pandemic processes. In a study investigating the SARS outbreak, 105 of the 305 cases reported were composed of healthcare professionals [14]. In another study, it was suggested that SARS-CoV and MERS-CoV viruses spread mainly through nosocomial transmission and that relatives of healthcare workers are more affected by infection [15]. This recent experience in the last decade has also caused concern in the Covid-19 pandemic, which has increased the anxiety levels of healthcare professionals. Also studies regarding 2003 SARS outbreak, showed that physicians and nurses feared contagion and transmision risk of infection to their families, friends, and colleagues [5], those health care workers felt uncertainty and stigmatization $[5,6]$, same thoughts occured in this outbreak also.

In some studies, psychological reactions were observed in health workers at the time of previous outbreaks $[5,16]$. Some employees had thoughts such as not wanting to go to work due to epidemics and thinking about resignation [17] and most of the health care workers have had high levels of stress, anxiety and depression symptoms [18]. Already in a study the psychological well-being of healthcare workers regardless of epidemic and pandemic was studied, they found nearly $30 \%$ of physicians and $20 \%$ of nurses suffering from depression, a rate 2-3 fold greater than the public [19]. The population of that study have shown minimal depression signs as in the rate of $40 \% ; 30.3 \%$ of the study have mild depression, $20.5 \%$ moderate and $8.2 \%$ of the physicians have shown severe depression signs. These results were compatible wtih the literature.

In a study examining 736 healthcare professionals, nurses and other healthcare workers during the Covid-19 pandemic and their social and psychological states, working conditions and social issues had been moderately affected from pandemics but their anxiety levels were found to be highly affected [20]. In our study, $83.7 \%$ of the physicians have displayed mild signs, $9.8 \%$ moderate and $6.5 \%$ have displayed severe anxiety signs.

In a study examining 1257 physicians, nurses and health workers working in different locations, Jianbo Lai et al. found depression findings (634 [50.4\%]), anxiety (560 [44.6\%]), insomnia (427 [34.0\%]), and distress (899 [71.5\%]). More depression, anxiety, and insomnia were observed among women employees, nurses and also those at the frontline employees in Wuhan. (eg, severe depression among physicians vs nurses: $24[4.9 \%]$ vs $54[7.1 \%]$ ) [21]. In parallel to aferomentioned studies, 1 our study, $41 \%$ of the pyhsicians have shown minimal depression signs, $30.3 \%$ mild, $20.5 \%$ moderate and $8.2 \%$ of the physicians have shown severe depression signs and $62.3 \%$ of physicians have mild, $29.5 \%$ of them have moderate and $8.2 \%$ have severe hopelessness signs. When considering the reasons of these psychological reactions; increasing workload, problems with having adequate personal protective equipment, confusing media news, not getting enough pshycologic and social support, infection rate among collegaues [22].

Healthcare workers are two of the five vocational groups with the highest prevalence of short sleep duration [23]. Although it is known that sleepiness issues are important for occupational and patient safety, have been underestimated like another issue: the mental health of caregivers [24]. In the study, carried out with 439 health care workers in 2018, Weaver et al. examined sleep disorders of health care givers and depression and anxiety conditions related with sleep disturbances. The sleep disoreder prevalence was $41 \%$, insomnia was the most common with $20 \%$, obstructive sleep apnea (9.4\%), restless legs syndrome (9.4\%), and not being a surprise, depression or anxiety was more commonly in the sleep disorder group [25]. Also in our study, as like aferomentioned study, $79.5 \%$ of physicians have shown 
mild and $20.5 \%$ of them have shown severe sleepiness signs. Likewise, anxiety levels of obstetricians and gynecologists have increased at the pandemic period, depression levels have increased strongly; hopes of physicians have decreased and slept off. As depression levels of obstetricians and gynecologists have increased, hopes of physicians have decreased and sleep problems increased.

The present study has limitations. Firstly, a longituidinal study design rather than a cross-sectional design might help confirming whether allostatic load increases and also psychiatric disorders may exacerbate with growing pandemic. Secondly, assessment was based on an online survey. In the future, assessments made in a clinic environment may contribute to more dramatic results about depression, anxiety problems with healthcare workers.

\section{Conclusion}

It is important to know, how to manage and improve the mental and psychological reactions of healthcare professionals to the situation under drastic working conditions such as pandemic. For that reason, it is important for healthcare system authorities to know the psychologic situations of their healtcare stuff. It is better to make this organisation as clinic and profession spesific. So, there is a need for many more studies that measure responses on a branch basis, such as this study; which will provide healthcare systems to make spesific interventions for each medical department to struggle with challenging pandemic conditions.

Disclosures: There is no conflict of interest for all authors.

Acknowledgements: The authors would like to thank all participants for their time and cooperation.

Statement of Ethics: All participants provided their online informed consent. The study was approved by the local ethics committee on human research.

\section{References}

1. Carlos WG, Dela Cruz CS, Cao B, Pasnick S, Jamil S. Novel Wuhan (2019-nCoV) Coronavirus. Am J Respir Crit Care Med. 2020; 201(4):P7-P8. doi:10.1164/rccm.2014P7

2. World Health Organization. Coronavirus (COVID-19) events as they happen. Web site: https://www.who.int/emergencies/diseases/ novelcoronavirus-2019/events-as-they-happen. [Accessed April 8, 2020].

3. Peeri, N. C., Shrestha, N., Rahman, M. S., Zaki, R., Tan, Z., Bibi, S., et al. The SARS, MERS and novel coronavirus (COVID-19) epidemics, the newest and biggest global health threats: what lessons have we learned? International journal of epidemiology. 2020; 49(3):717-726. https://doi.org/10.1093/ije/dyaa033

4. Li, X., Yu, H., Bian, G., Hu, Z., Liu, X., Zhou, Q., et al. Prevalence, risk factors, and clinical correlates of insomnia in volunteer and at home medical staff during the COVID-19. Brain, behavior, and immunity. 2020; 87:140-141. https://doi.org/10.1016/j.bbi.2020.05.008

5. Fischer, J. E., \& Katz, R. Moving forward to 2014: global IHR (2005) implementation. Biosecurity and bioterrorism: biodefense strategy, practice, and science. 2013; 11(2):153-156. https://doi.org/10.1089/bsp.2013.0030

6. Moon, S. Will Ebola change the game? Ten essential reforms before the next pandemic. The report of the Harvard-LSHTM. Independent Panel on the Global Response to Ebola. The Lancet. 2015; 386: 2204-2221.

7. Greenberg, N., Docherty, M., Gnanapragasam, S., \& Wessely, S. Managing mental health challenges faced by healthcare workers during covid-19 pandemic. BMJ (Clinical research ed.). 2020; 368:m1211. https://doi.org/10.1136/bmj.m1211

8. Verma, S., Mythily, S., Chan, Y. H., Deslypere, J. P., Teo, E. K., \& Chong, S. A. Post-SARS psychological morbidity and stigma among general practitioners and traditional Chinese medicine practitioners in Singapore. Annals of the Academy of Medicine, Singapore. 2004; 33(6):743-748.

9. Substance Abuse and Mental Health services Administration. DSM-IV to DSM-5 Acute Stress Disorder Comparison. www.ncbi.nlm. nih.gov/books/NBK519704/table/ ch3.t30/ (2016, accessed 31 March 2020).

10. Spencer S, Nolan J, Osborn M, Georgiou A. The presence of psychological trauma symptoms in resuscitation providers and an exploration of debriefing practices. Resuscitation. 142:175-181. DOI: https://doi.org/10.1016/j.resuscitation.2019.06.280

11. Coşkun R, Altunışık, R, Yildirim E. Research methods in Social Sciences (SPSS applied). 2017; Adapazarı: Sakarya Bookstore.

12. Karagoz Y. SPSS and AMOS Applied scientific research methods and publishing ethics, 2017; Ankara: Nobel Publication Distribution.

13. Zhong, N. S., Zheng, B. J., Li, Y. M., Poon, Xie, Z. H., Chan, K. H., et al. Epidemiology and cause of severe acute respiratory syndrome (SARS) in Guangdong, People's Republic of China, in February, 2003. Lancet (London, England). 2003; 362(9393):1353-1358. https://doi.org/10.1016/s0140-6736(03)14630-2

14. de Wit, E., van Doremalen, N., Falzarano, D., \& Munster, V. J. SARS and MERS: recent insights into emerging coronaviruses. Nature reviews. Microbiology. 2016; 14(8):523-534. https://doi.org/10.1038/nrmicro.2016.81

15. Chua, S. E., Cheung, V., Cheung, C., McAlonan, G. M., Wong, J. W., Cheung, E. P., et al. Psychological effects of the SARS outbreak in Hong Kong on high-risk health care workers. Canadian journal of psychiatry. Revue canadienne de psychiatrie. 2004; 49(6):391-393. https://doi.org/10.1177/070674370404900609

16. Bai, Y., Lin, C. C., Lin, C. Y., Chen, J. Y., Chue, C. M., \& Chou, P. Survey of stress reactions among health care workers involved with the SARS outbreak. Psychiatric services (Washington, D.C.). 2004; 55(9):1055-1057. https://doi.org/10.1176/appi.ps.55.9.1055

17. 18. Lee, A. M., Wong, J. G., McAlonan, G. M., Cheung, V., Cheung, C., Sham, P. C., et al. Stress and psychological distress among SARS survivors 1 year after the outbreak. Canadian journal of psychiatry. Revue canadienne de psychiatrie. 2007; 52(4):233-240. https://doi.org/10.1177/070674370705200405

18. Mata, D. A., Ramos, M. A., Bansal, N., Khan, R., Guille, C., Di Angelantonio, E., \& Sen, S. Prevalence of Depression and Depressive Symptoms Among Resident Physicians: A Systematic Review and Meta-analysis. JAMA. 2015; 314(22):2373-2383. https://doi. org/10.1001/jama.2015.15845 
19. Bostan S, Akbolat M, Kaya A, Ozata M, Gunes D. Assessments of Anxiety Levels and Working Conditions of Health Employees Working in COVID-19 Pandemic Hospitals. Electron J Gen Med. 2020; 17(5):em246. https://doi.org/10.29333/ejgm/8228

20. Lai, J., Ma, S., Wang, Y., Cai, Z., Hu, J., Wei, N., et al. Factors Associated With Mental Health Outcomes Among Health Care Workers Exposed to Coronavirus Disease 2019. JAMA network open. 2020; 3(3):e203976. https://doi.org/10.1001/jamanetworkopen.2020.3976

21. Cai, H., Tu, B., Ma, J., Chen, L., Fu, L., Jiang, Y., et al.. Psychological Impact and Coping Strategies of Frontline Medical Staff in Hunan Between January and March 2020 During the Outbreak of Coronavirus Disease 2019 (COVID 19) in Hubei, China. Medical science monitor: international medical journal of experimental and clinical research. 2020; 26:e924171. https://doi.org/10.12659/MSM.924171.

22. Shockey, T. M., \& Wheaton, A. G. Short Sleep Duration by Occupation Group - 29 States, 2013-2014. MMWR. Morbidity and mortality weekly report. 2017; 66(8):207-213. https://doi.org/10.15585/mmwr.mm6608a2

23. Croskerry P. Comment in The philosophy of medicine. CMAJ. 2010; 182(5):524. doi:10.1503/cmaj.100270. Epub 2010 Mar 15.

24. Weaver, M. D., Vetter, C., Rajaratnam, S., O'Brien, C. S., Qadri, S., Benca, R. M., et al. Sleep disorders, depression and anxiety are associated with adverse safety outcomes in healthcare workers: A prospective cohort study. Journal of sleep research. 2018; 27(6):e12722. https://doi.org/10.1111/jsr.12722 